\title{
High Lymph Node Yield is Related to Microsatellite Instability in Colon Cancer
}

\author{
E. J. Th. Belt, $\mathrm{MD}^{1,2}$, E. A. te Velde, MD, $\mathrm{PhD}^{1}$, O. Krijgsman ${ }^{3}$, R. P. M. Brosens, MD, $\mathrm{PhD}^{1,4}$, M. Tijssen ${ }^{3}$, \\ H. F. van Essen ${ }^{3}$, H. B. A. C. Stockmann, MD, $\mathrm{PhD}^{2}$, H. Bril, MD, $\mathrm{PhD}^{5}$, B. Carvalho, $\mathrm{PhD}^{3}$, B. Ylstra, $\mathrm{PhD}^{3}$, \\ H. J. Bonjer, MD, $\mathbf{P h D}^{1}$, and G. A. Meijer, $\mathrm{MD}, \mathbf{P h D}^{3}$ \\ ${ }^{1}$ Department of Surgery, VU University Medical Centre, Amsterdam, The Netherlands; ${ }^{2}$ Department of Surgery, \\ Kennemer Gasthuis, Haarlem, The Netherlands; ${ }^{3}$ Department of Pathology, VU University Medical Centre, Amsterdam, \\ The Netherlands; ${ }^{4}$ Department of Surgery, Zaans Medical Centre, Zaandam, The Netherlands; ${ }^{5}$ Department of Pathology, \\ Kennemer Gasthuis, Haarlem, The Netherlands
}

\begin{abstract}
Background. Lymph node (LN) yield in colon cancer resection specimens is an important indicator of treatment quality and has especially in early-stage patients therapeutic implications. However, underlying disease mechanisms, such as microsatellite instability (MSI), may also influence LN yield, as MSI tumors are known to exhibit more prominent lymphocytic antitumor reactions. The aim of the present study was to investigate the association of LN yield, MSI status, and recurrence rate in colon cancer.

Methods. Clinicopathological data and tumor samples were collected from 332 stage II and III colon cancer patients. DNA was isolated and PCR-based MSI analysis performed. LN yield was defined as "high" when 10 or more LNs were retrieved and "low" in case of fewer than 10 LNs.

Results. Tumors with high LN yield were significantly associated with the MSI phenotype (high LN yield: $26.3 \%$ MSI tumors vs low LN yield: $15.1 \%$ MSI tumors; $P=.01$ ), mainly in stage III disease. Stage II patients with high LN yield had a lower recurrence rate compared with those with low LN yield. Patients with MSI tumors tended to develop fewer recurrences compared with those with MSS tumors, mainly in stage II disease.

Conclusions. In the present study, high LN yield was associated with MSI tumors, mainly in stage III patients.
\end{abstract}

(C) The Author(s) 2011. This article is published with open access at Springerlink.com

First Received: 10 March 2011;

Published Online: 12 October 2011

G. A. Meijer, MD, PhD

e-mail: ga.meijer@vumc.nl
Besides adequate surgery and pathology, high LN yield is possibly a feature caused by biologic behavior of MSI tumors.

Colorectal cancer (CRC) is the third most common form of cancer and the second leading cause of cancer-related death in the Western world, with more than 600,000 deaths worldwide each year. ${ }^{1}$

Currently, the tumor-node-metastasis (TNM) staging system, developed by the American Joint Committee on Cancer (AJCC) and the International Union Against Cancer (UICC), is the primary method for assessing prognosis for individual patients. ${ }^{2}$

For patients with lymph node metastases (TNM stage III), adjuvant chemotherapy after resection of the primary tumor is recommended, because of high risk for disease recurrence. Adjuvant 5-fluorouracil (5-FU)-based chemotherapy has been found to increase median 5 -year survival in stage III colon cancer patients from $51 \%$ to $64 \%$. $^{3}$ Moreover, combinations of 5-FU-based therapy with oxaliplatin have further improved response rates and diseasefree survival. ${ }^{4}$ However, so far no convincing evidence exists for a beneficial effect of postoperative adjuvant chemotherapy in patients without lymph node metastases (TNM stage I and II), while $20 \%-30 \%$ of stage II patients will still develop recurrent disease. ${ }^{5,6}$ One of the dilemmas here is the number of lymph nodes actually required for making an accurate call of stage II colon cancer. In fact, numbers ranging from as low as 4 to as high as 40 nodes have been suggested for adequate staging..$^{7-18}$ Although most current recommendations stick to a minimum number of 10-12 lymph nodes to be investigated, in routine clinical 
practice this is certainly not always achieved. ${ }^{19-21}$ Besides its pivotal role in accurate staging, a high lymph node yield has been associated with a better prognosis in both stage II and III colon cancer, an observation for which no clear biological explanation has been found. ${ }^{9}, 12,15,18,22-25$

Extent of surgical resection and thorough pathological evaluation of the resection specimen play an important role in the total number of lymph nodes identified. Moreover, underlying disease mechanisms of colon cancer may have an important effect on lymph node harvest as well. Possibly, biological behavior of the tumor and interactions between tumor and host affect characteristics of peritumoral lymph nodes resulting in improved node yield. One of the underlying biological factors that has been suggested to influence the number of lymph nodes retrieved in the resection specimens is the microsatellite instability status of colon cancer, which in itself is also associated with clinical outcome. ${ }^{26}$ The aim of the present study was to investigate the association of lymph node yield, MSI status, and recurrence rate in stage II and III colon cancer patients.

\section{PATIENTS AND METHODS}

From 1996 to 2005, a total of 667 patients underwent surgical resection for colon cancer at the Kennemer Gasthuis hospital in Haarlem, the Netherlands. Of these, 454 were classified as TNM stage II (T3-4, N0, M0) or III (T1-4, N1-2, M0) according to the TNM staging system by the AJCC and UICC. ${ }^{27}$

Data were collected from clinical reports and included date of birth, date of surgery, location of the primary tumor, that is, right-sided (caecal, ascending, transverse) or left-sided (descending, sigmoid, rectosigmoid), adjuvant chemotherapy, date and site of first disease recurrence, and cause of death, that is, colon cancer related or unrelated cause of death. Disease recurrence was defined as either local tumor recurrence or distant metastases, diagnosed by computed tomography imaging and/or histopathology.

From the histopathology reports, information was retrieved about tumor size, tumor and nodal stage, differentiation grade, ulceration, mucinous differentiation, and angioinvasion of the primary tumor. In line with the Dutch national guidelines, lymph node (LN) yield was defined as "high" when 10 or more LNs were retrieved and "low" in case of fewer than 10 LNs.

Patients with a previous history of colorectal malignancy $(n=12)$ and those with incomplete resections of the primary tumor (macroscopically or microscopically, $n=9$ ) were excluded from this study. Also patients who were lost for follow-up or died within 3 months after surgery ( $n=8$ and $n=39$, respectively) were excluded. Of the 386 eligible patients, microsatellite instability status could not be determined in 54 cases (see the section "Microsatellite Instability Analysis"), which were also excluded from this study.

The remaining study population consisted of 332 stage II and III colon cancer patients: 181 males and 151 females with a mean age of 70 years and a median follow-up period of more than 57 months (Table 1). Adjuvant 5-FU-based chemotherapy was administered to $15.7 \%$ of stage II patients and $55.8 \%$ of stage III patients.

\section{Lymph Node Retrieval and Examination}

After resection of the colon, the specimens were placed in formalin and allowed to fix for at least 24 hours. After proper fixation, the mesenteric fat was cut into thin slices and lymph nodes were sampled: small lymph nodes not exceeding $5 \mathrm{~mm}$ in diameter were included in toto, somewhat larger lymph nodes (diameter $5-10 \mathrm{~mm}$ ) were cut in half, and lymph nodes larger than $10 \mathrm{~mm}$ were sliced in equal intervals and subsequently placed in marked cassettes. After conventional histological staining with hematoxylin and eosin, the lymph nodes were microscopically examined for the presence of metastases.

\section{DNA Isolation}

DNA was isolated from formalin-fixed paraffin-embedded (FFPE) colon cancer tissues samples. For each tumor, areas with at least $70 \%$ tumor cells were selected from $4-\mu \mathrm{m}$ sections. Adjacent serial sections of $10 \mu \mathrm{m}$ were cut and macrodissected. DNA was isolated as previously described (using QIAamp microkit; Qiagen, Hilden, Germany). ${ }^{28}$ DNA concentrations were measured with a Nanodrop-100 spectrophotometer (Isogen, De Meern, The Netherlands).

\section{Microsatellite Instability Analysis}

Tumor samples were analyzed for microsatellite instability (MSI) using MSI Analysis System, Version 1.2 according to the manufacturer's instructions (Promega, Madison, WI). This PCR-based assay uses 5 mononucleotide repeat markers to determine MSI status. PCR products were separated by capillary electrophoresis using the ABI 3130 DNA sequencer, and output data were analyzed using the accompanying package GeneScan 3100 (Applied Biosystems, Foster City. CA). Tumors were classified as microsatellite instable (MSI) when instability was observed for 2 or more markers. When instability was observed for none or only 1 marker, tumors were considered to be microsatellite stable (MSS). MSI status could be determined in 332 cases, (i.e., $86 \%$ of tumor samples, while 
TABLE 1 Clinical and pathological characteristics of study population

\begin{tabular}{|c|c|c|c|c|}
\hline & Overall $(n=332)$ & $\mathrm{LN}<10(n=199)$ & $\mathrm{LN} \geq 10(n=133)$ & $P$ value \\
\hline \multicolumn{5}{|l|}{ Sex } \\
\hline Male & $181(54.5)$ & $109(54.8)$ & $72(54.1)$ & \\
\hline Female & $151(45.5)$ & $90(45.2)$ & $61(45.9)$ & NS \\
\hline \multicolumn{5}{|l|}{ Age (years) } \\
\hline Mean (s.d.) & $70.6(12.1)$ & $71.4(12.3)$ & $69.5(11.7)$ & \\
\hline Median (range) & $72.8(28.5-94.0)$ & $73.4(28.5-94.0)$ & $71.9(34.5-91.3)$ & NS \\
\hline \multicolumn{5}{|l|}{ Tumor location } \\
\hline Right sided & 148 (44.6) & $78(39.2)$ & $70(52.6)$ & \\
\hline Left sided & $184(55.4)$ & $121(60.8)$ & $63(47.4)$ & .02 \\
\hline Tumor size (mm), Mean (s.d) & $42.4(20.1)$ & $40.4(20.1)$ & $45.4(20.0)$ & .03 \\
\hline \multicolumn{5}{|l|}{ Tumor stage } \\
\hline T1 & $4(1.2)$ & $3(1.5)$ & $1(0.8)$ & \\
\hline $\mathrm{T} 2$ & $18(5.4)$ & $12(6.0)$ & $6(4.5)$ & \\
\hline T3 & $277(83.4)$ & $160(80.4)$ & $117(88.0)$ & \\
\hline $\mathrm{T} 4$ & $33(9.9)$ & $24(12.1)$ & $9(6.8)$ & NS \\
\hline \multicolumn{5}{|l|}{ Microsatellite instability status } \\
\hline MSS & $267(80.4)$ & $169(84.9)$ & $98(73.7)$ & \\
\hline MSI & 65 (19.6) & $30(15.1)$ & $35(26.3)$ & .01 \\
\hline \multicolumn{5}{|l|}{ Histological differentiation grade } \\
\hline Poorly & $48(14.5)$ & $28(14.1)$ & $20(15.0)$ & \\
\hline Moderately/well & $284(85.5)$ & $171(85.9)$ & $113(80.0)$ & NS \\
\hline \multicolumn{5}{|l|}{ Mucinous differentiation } \\
\hline Yes & $66(19.9)$ & $42(21.1)$ & $24(18.0)$ & \\
\hline No & $266(80.1)$ & 157 (78.9) & $109(82.0)$ & NS \\
\hline \multicolumn{5}{|l|}{ Ulceration } \\
\hline Present & 258 (77.7) & $150(75.4)$ & $108(81.2)$ & \\
\hline Absent & $74(22.3)$ & $49(24.6)$ & $25(18.8)$ & NS \\
\hline \multicolumn{5}{|l|}{ Angioinvasion } \\
\hline Present & $73(22.0)$ & 39 (19.6) & $34(25.6)$ & \\
\hline Absent & $259(78.0)$ & $160(80.4)$ & $99(74.4)$ & NS \\
\hline \multicolumn{5}{|l|}{ TNM stage } \\
\hline Stage II & $185(55.7)$ & $118(59.3)$ & $67(50.4)$ & \\
\hline Stage III & $147(44.3)$ & $81(40.7)$ & $66(49.6)$ & NS \\
\hline \multicolumn{5}{|l|}{ Recurrence } \\
\hline Yes & $113(34.0)$ & $75(37.7)$ & 38 (28.6) & \\
\hline No & $219(66.0)$ & $124(62.3)$ & $95(71.4)$ & .09 \\
\hline Follow up (months), median (range) & $57.1(3.5-148.6)$ & $54.0(4.3-142.6)$ & $61.8(3.5-148.6)$ & .06 \\
\hline
\end{tabular}

MSI microsatellite instable tumors, MSS microsatellite stable tumors, NS not significant

Values in parentheses are percentages unless stated otherwise

attempts to characterize the remaining $14 \%$ failed because of insufficient quality of the FFPE-derived DNA material).

\section{Statistical Analysis}

Differences between sample means were determined using the $t$ test. Differences in proportions between groups were examined using Pearson's chi-square test. Survival rates were displayed using the Kaplan-Meier method and compared using the log-rank test. All reported $P$ values are 2 -sided, and a significance level of .05 was used. Statistical analysis was performed with SPSS 17.0 for Windows, SPSS Inc., Chicago, IL.

\section{RESULTS}

Of the 185 stage II patients, $24.9 \%$ developed recurrent disease, while for the 147 stage III patients this was $45.6 \%$ 
$(P<.01)$. An overview of disease recurrence rates is displayed in Table 2. No difference in mean lymph node retrieval was observed over time and between involved surgeons and pathologists (data not shown).

High LN yield was observed in 133 patients (40.1\%) and low lymph node yield ( $<10 \mathrm{LN})$ in 199 (59.9\%) patients. Overall, patients with high LN yield tended to have fewer recurrences compared with patients with low LN yield (28.6\% vs $37.7 \%, P=.09$ ). Considering only stage II patients, there was a significant difference in recurrence rate, namely, $16.4 \%$ for patients with high LN (11 of 67) yield and $29.7 \%$ for patients with low LN yield (35 of $118 ; P=.05$ ). Disease-free survival curves are displayed in Fig. 1.

Tumors with high LN yield were significantly larger and were located more frequently right-sided compared with tumors with low LN yield (mean $45.4 \mathrm{~mm}$ vs $40.4 \mathrm{~mm}$, respectively, $P=.03$; right-sided $60.8 \%$ vs $47.2 \%$, respectively, $P=.02$ ).

Tumors with high LN yield were significantly associated with the MSI phenotype, as $26.3 \%$ of these tumors were

TABLE 2 Disease recurrence rates in 332 stage II and III colon cancer patients

\begin{tabular}{|c|c|c|c|c|}
\hline & \multicolumn{4}{|c|}{ Stage II + III recurrence rate } \\
\hline & Total $(n=332)$ & $\operatorname{MSI}(n=65)$ & $\operatorname{MSS}(n=267)$ & $P$ value \\
\hline Total $(n=332)$ & $34.0 \%$ & $24.6 \%(16 / 65)$ & $36.3 \%(97 / 267)$ & .07 \\
\hline $\mathrm{LN}<10(n=199)$ & $37.7 \%$ & $30.0 \%(9 / 30)$ & $39.1 \%(66 / 169)$ & NS \\
\hline $\mathrm{LN} \geq 10(n=133)$ & $28.6 \%$ & $20.0 \%(7 / 35)$ & $31.6 \%(31 / 98)$ & NS \\
\hline \multirow[t]{3}{*}{$P$ value } & .09 & NS & NS & \\
\hline & \multicolumn{4}{|c|}{ Stage II recurrence rate } \\
\hline & Total $(n=185)$ & $\operatorname{MSI}(n=38)$ & $\operatorname{MSS}(n=147)$ & $P$ value \\
\hline Total $(n=185)$ & $24.9 \%$ & $13.2 \%(5 / 38)$ & $27.9 \%(41 / 147)$ & .06 \\
\hline $\mathrm{LN}<10(n=118)$ & $29.7 \%$ & $18.2 \%(4 / 22)$ & $32.3 \%(31 / 96)$ & NS \\
\hline $\mathrm{LN} \geq 10(n=67)$ & $16.4 \%$ & $6.3 \%(1 / 16)$ & $19.6 \%(10 / 51)$ & NS \\
\hline \multirow[t]{3}{*}{$P$ value } & .05 & NS & .10 & \\
\hline & \multicolumn{4}{|c|}{ Stage III recurrence rate } \\
\hline & Total $(n=147)$ & $\operatorname{MSI}(n=27)$ & $\operatorname{MSS}(n=120)$ & $P$ value \\
\hline Total $(n=147)$ & $45.6 \%$ & $40.7 \%(11 / 27)$ & $46.7 \%(56 / 120)$ & NS \\
\hline $\mathrm{LN}<10(n=81)$ & $49.4 \%$ & $62.5 \%(5 / 8)$ & $47.9 \%(35 / 73)$ & NS \\
\hline $\mathrm{LN} \geq 10(n=66)$ & $40.9 \%$ & $31.6 \%(6 / 19)$ & $44.7 \%(21 / 47)$ & NS \\
\hline$P$ value & NS & NS & NS & \\
\hline
\end{tabular}

$M S I$ microsatellite instable tumors, $M S S$ microsatellite stable tumors, NS not significant

FIG. 1 Disease-free survival curves of colon cancer patients with high $(\geq 10)$ and low $(<10)$ lymph node $(\mathrm{LN})$ yield for (a) stage II and (b) stage III patients
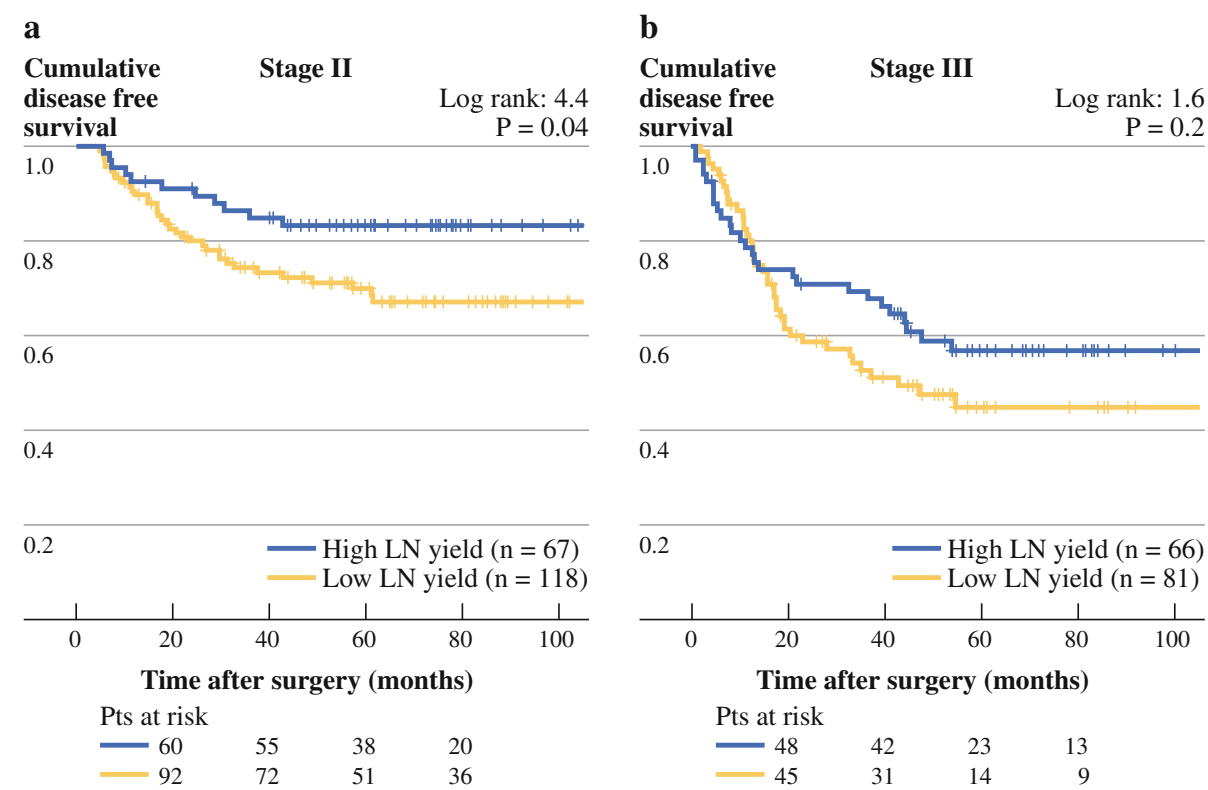
MSI, compared with $15.1 \%$ of tumors with low LN yield $(P=.01)$. The mean LN yield of resected MSI tumors was 10.1 compared with 8.6 for MSS tumors $(P=.03$; Fig. 2a). This difference though, was mainly observed in stage III patients (Fig. 2b, c). For this subgroup, the mean LN yield for MSI tumors was 11.7, compared with 9.1 for MSS tumors $(P<.01)$.

\section{MSI vs MSS Tumors}

Of all tumors, $19.6 \%$ appeared to be MSI and $80.4 \%$ MSS. Disease recurrence occurred in $24.6 \%$ of the patients with MSI tumors, compared with $36.3 \%$ of the patients with MSS tumors $(P=.07)$. This difference was mainly attributable to stage II patients, as in this group the recurrence rate was $13.2 \%$ for patients with MSI tumors and $27.9 \%$ in MSS cases $(P=.06)$. For stage III patients, recurrence rates were $40.7 \%$ for MSI tumors and $46.7 \%$ in case of MSS tumors $(P=.6)$. Disease-free survival curves are depicted in Fig. 3.

FIG. 2 Box plot analysis comparing number of lymph nodes retrieved between colon cancer patients with MSS tumors and patients with MSI tumors for the total patient population (MSS: $n=267$, MSI: $n=65$, [a]) and separately for stage II (MSS: $n=147$, MSI: $n=38$, [b]) and stage III (MSS: $n=120$, MSI: $n=27,[\mathbf{c}])$ patients

FIG. 3 Disease-free survival curves of colon cancer patients with MSS tumors and patients with MSI tumors for (a) stage II and (b) stage III patients
MSI tumors revealed a poor histological differentiation in $30.8 \%$ compared with only $10.5 \%$ in cases of MSS tumors $(P<.01)$. MSI tumors were located more often right-sided, compared with MSS tumors $(62.9 \%$ vs $24.6 \%$, respectively, $P<.01$ ) and were significantly larger (mean $54.2 \mathrm{~mm}$ vs $39.6 \mathrm{~mm}, P<.01)$.

Within the patient population with MSI tumors, a trend toward better disease-free survival was seen for those with high LN yield compared with patients with low LN yield, as shown in Fig. 4a. For patients with MSS tumors, a similar trend was observed (Fig. 4b). When these analyses were performed stratified for disease stage, no significant differences in survival between patients with high LN yield and those with low LN yield were seen (data not shown).

\section{Multivariate Analysis}

Multivariate analysis included sex, age, disease stage, MSI status, tumor location, tumor diameter, differentiation grade, presence of mucinous differentiation, ulceration, and
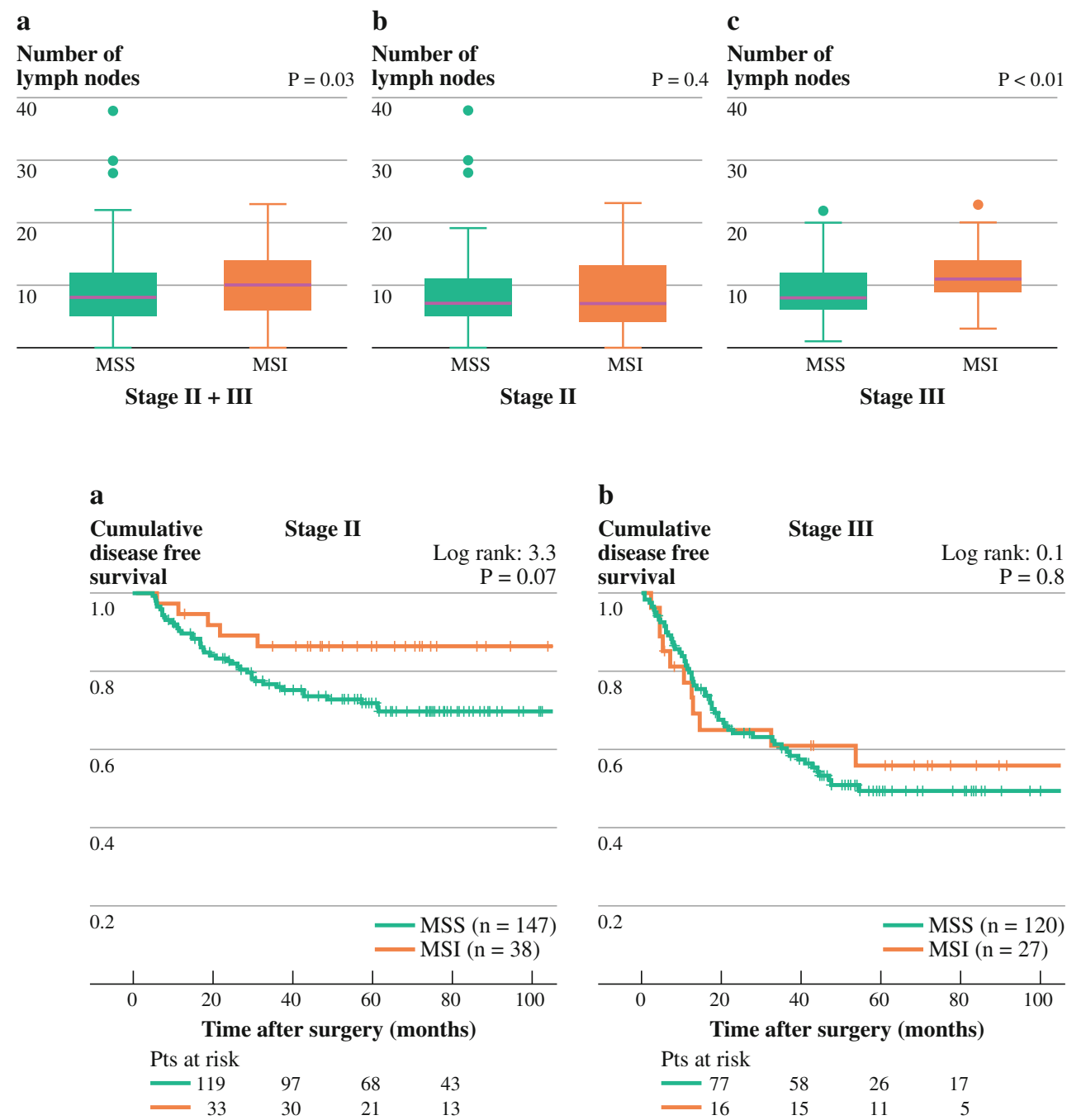
FIG. 4 Disease-free survival curves of microsatellite instable (MSI) (a) and microsatellite stable (MSS) (b) colon cancer patients with high $(\geq 10)$ and low $(<10)$ lymph node $(\mathrm{LN})$ yield

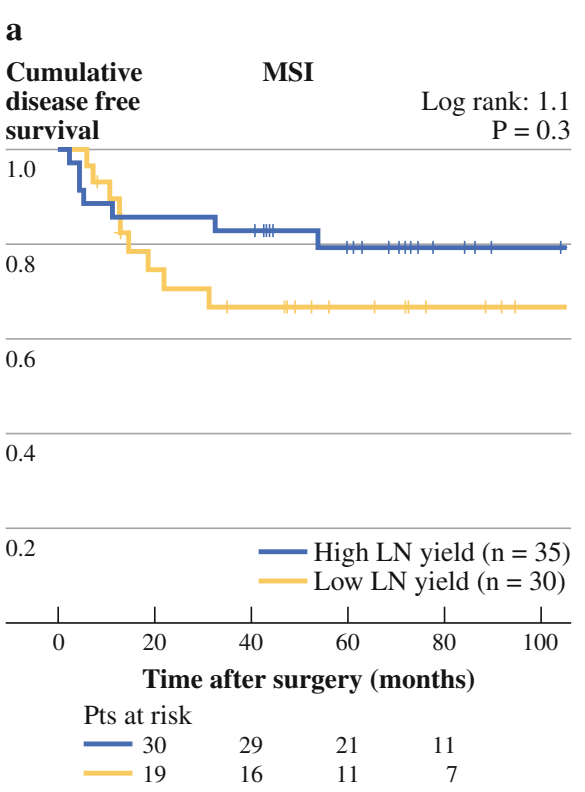

angioinvasion. MSI phenotype was the strongest independent factor associated with high lymph node yield (odds ratio $2.3,95 \%$ confidence interval $1.2-4.4$ ).

\section{DISCUSSION}

In the present study, high $\mathrm{LN}$ yield in the resection specimen was associated with improved disease-free survival. This was observed mainly in stage II patients, while for stage III patients only a trend toward better survival was seen in cases of high LN yield. Regarding stage II patients, we identified high-risk patients based on NCCN criteria. ${ }^{29}$ We analyzed T-stage, histologic grade, vascular invasion, and number of lymph nodes sampled of all tumor specimens. These characteristics are included in Table 1 and Fig. 2. For these characteristics, no significant difference was observed between patients with low lymph node count $(<10)$ and those with high lymph node count $(\geq 10)$, as shown in Table 1.

Several studies strongly confirm the association between high LN yield and improved survival in colorectal cancer patients, both in stage II and III disease. . $^{15,18,25,30,31}$

The causal factors for this association are subject of debate. Stage migration has been postulated as a factor. Patients with lower numbers of nodes analyzed could be falsely designated as stage I or stage II, when the nodes examined contain no metastases, while additional node samples would have revealed tumor and thus stage III would have been assigned.

Moreover, resection of lymph nodes itself may have a therapeutic effect. For patients with positive lymph nodes, a higher number of recovered nodes has been associated with better survival. ${ }^{15,25,31-33}$ This was not strongly confirmed by the present study as stage III patients with high LN yield showed only a trend toward better diseasefree survival.

Several explanations have been postulated to explain why some resection specimens of colon cancer have high lymph node yields and others do not. It has been suggested that a low number of nodes recovered in a specimen is a reflection of inadequate surgical resection or pathological examination. $^{34-36}$ Guidelines recommending a certain minimum number of investigated lymph nodes are also based on the assumption that increased effort by the surgeon and pathologist will lead to higher lymph node counts. However, large studies that show inferior survival in colon cancer patients with fewer lymph nodes demonstrated that this relationship could not be explained by factors such as extent of surgical resection and pathologic processing. ${ }^{30,37}$ Moreover, the fact that most societies nowadays recommend a minimum number of 10 to 12 lymph nodes to be investigated, and this is only achieved in about one-third to one-half of the patients, also indicates that other factors besides surgical and pathologic skills may play a role in lymph node yield. ${ }^{19-21}$ Alternatively, a low number of nodes may not necessarily represent the quality of care a patient has received and instead may be influenced by underlying biological characteristics of the tumors.

One of the underlying biological factors that have been suggested to be of influence is the microsatellite instability status of colon cancer. Microsatellite instability is 1 of 2 major distinct colorectal oncogenic pathways, the other being chromosomal instability. ${ }^{38-40}$ Microsatellite instability is observed in about $15 \%$ of sporadic colorectal cancers and is caused by a defect in the DNA mismatch 
repair system. Colon cancers with the MSI phenotype have been associated with a better prognosis compared with MSS tumors. ${ }^{38,40,41}$ One of the factors involved here could be the antitumor immune response, which differs between MSI and MSS colorectal cancers. In general, the immune system recognizes neoplasia poorly, but in MSI colon cancer with infiltrating lymphocytes, it has been shown that mechanisms of T-cell cytotoxicity are activated. ${ }^{42}$

Truncated peptides produced by frameshift mutations that are common in MSI cancers because of failing DNA mismatch repair may be immunogenic and contribute to the host immune response resulting in the migration of activated T-cells into the malignant epithelium of the tumor. ${ }^{43-50}$ Moreover, marked lymphocytic, so-called "Crohn's-like" infiltrates are a hallmark of MSI colorectal cancers. ${ }^{51}$ Microscopically, hyperplastic changes are seen in lymph nodes draining colorectal tumors exhibiting prominent antitumor immune reactions, and these tumors were found to have larger and more detectable lymph nodes. ${ }^{52,53}$ These findings suggest a relation between MSI status of the primary tumor and lymph node yield in the resection specimen. This is supported by the present study, as MSI tumors were significantly associated with a high number of lymph nodes harvested (Fig. 2a).

The association between MSI phenotype and high lymph node yield as was observed in the present study has been reported before in 2 smaller and more heterogeneous study populations compared with the present one. ${ }^{54,55}$ One study consisted of 82 stage I $(n=27)$ and II $(n=55)$ both colon $(n=52)$ and rectal $(n=30)$ cancers, the other was based on 121 stage I-III colon cancers (12 stage I, 71 stage II, and 38 stage III patients). ${ }^{54,55}$ In the present study, rectal cancers were excluded, because in general these tumors are treated with preoperative (chemo)radiation therapy, which is known to influence lymph node retrieval of the resection specimen. ${ }^{56-58}$ In both earlier studies, heterogeneous patient populations were investigated and analysis did not include, in contrast to the present study, stratification for disease stage, possibly because the relatively small sample sizes would not allow for meaningful subgroup analysis.

The present study consisted of 185 stage II and 147 stage III colon cancer patients. This is the first study reporting a significant association between MSI tumors and high LN yield in stage III colon cancer. Interestingly, the effect of MSI on lymph node yield was highest in stage III cancer, that is, in those tumors in which metastatic spread to regional lymph has already occurred. This could be caused by an additional boost of the immune response due to more intimate exposure of lymphoid tissue to tumor cells than in stage II tumors.

In conclusion, the present study showed a strong association between MSI phenotype and high lymph node yield in colon cancer, mainly so in stage III disease. The biology of MSI colon cancers can provide explanations for this, while at the same time contributing to a better prognosis. Conversely, a less favorable outcome in patients with lower lymph node yields would then not only be attributable to understaging due to missed positive lymph nodes, but also to tumor intrinsic factors.

ACKNOWLEDGMENT This study was supported by a grant from the Posthumus Meyjes Foundation of the Kennemer Gasthuis hospital, Haarlem, The Netherlands.

OPEN ACCESS This article is distributed under the terms of the Creative Commons Attribution Noncommercial License which permits any noncommercial use, distribution, and reproduction in any medium, provided the original author(s) and source are credited.

\section{REFERENCES}

1. World Health Organisation, Data and statistics. www. who.int/mediacentre/factsheets/fs297/en. Accessed 30 Dec 2010.

2. Sobin L, Gospodarowicz M, Wittekind C. TNM Classification of malignant tumours. 7th ed. Chichester, U.K.: Wiley; 2009.

3. Gill S, Loprinzi CL, Sargent DJ, Thomé SD, Alberts SR, Haller DG, et al. Pooled analysis of fluorouracil-based adjuvant therapy for stage II and III colon cancer: who benefits and by how much? J Clin Oncol. 2004;22:1797-806.

4. Andre T, Boni C, Mounedji-Boudiaf L, Navarro M, Tabernero J, Hickish T, et al. Oxaliplatin, fluorouracil, and leucovorin as adjuvant treatment for colon cancer. N Engl J Med. 2004;350:2343-51.

5. Efficacy of adjuvant fluorouracil and folinic acid in B2 colon cancer. International Multicentre Pooled Analysis of B2 Colon Cancer Trials (IMPACT B2) Investigators. J Clin Oncol. 1999; 17:1356-63.

6. Mamounas E, Wieand S, Wolmark N, Bear HD, Atkins JN, Song $\mathrm{K}$, et al. Comparative efficacy of adjuvant chemotherapy in patients with Dukes' B versus Dukes' C colon cancer: results from four National Surgical Adjuvant Breast and Bowel Project adjuvant studies (C-01, C-02, C-03, and C-04). J Clin Oncol. 1999; 17:1349-55.

7. Goldstein NS, Sanford W, Coffey M, Layfield LJ. Lymph node recovery from colorectal resection specimens removed for adenocarcinoma. Trends over time and a recommendation for a minimum number of lymph nodes to be recovered. Am J Clin Pathol. 1996;106:209-16.

8. Hernanz F, Revuelta S, Redondo C, Madrazo C, Castillo J, Gomez-Fleitas M. Colorectal adenocarcinoma: quality of the assessment of lymph node metastases. Dis Colon Rectum. 1994;37:373-6; discussion 376-7.

9. Swanson RS, Compton CC, Stewart AK, Bland KI. The prognosis of T3N0 colon cancer is dependent on the number of lymph nodes examined. Ann Surg Oncol. 2003;10:65-71.

10. Vather R, Sammour T, Zargar-Shoshtari K, Metcalf P, Connolly A, Hill A. Lymph node examination as a predictor of long-term outcome in Dukes B colon cancer. Int J Colorectal Dis. 2009;24:283-8.

11. Wong JH, Severino R, Honnebier MB, Tom P, Namiki TS. Number of nodes examined and staging accuracy in colorectal carcinoma. J Clin Oncol. 1999;17:2896-900.

12. Caplin S, Cerottini JP, Bosman FT, Constanda MT, Givel JC. For patients with Dukes' B (TNM Stage II) colorectal carcinoma, examination of six or fewer lymph nodes is related to poor prognosis. Cancer. 1998;83:666-72. 
13. Chen SL, Bilchik AJ. More extensive nodal dissection improves survival for stages I to III of colon cancer: a population-based study. Ann Surg. 2006;244:602-10.

14. Joseph NE, Sigurdson ER, Hanlon AL, Wang H. Accuracy of determining nodal negativity in colorectal cancer on the basis of the number of nodes retrieved on resection. Ann Surg Oncol. 2003;10:213-8.

15. Le Voyer TE, Sigurdson ER, Hanlon AL, Mayer RJ, Macdonald JS, Catalano PJ, et al. Colon cancer survival is associated with increasing number of lymph nodes analyzed: a secondary survey of intergroup trial INT-0089. J Clin Oncol. 2003;21:2912-9.

16. Cianchi F, Palomba A, Boddi V, Messerini L, Pucciani F, Perigli $\mathrm{G}$, et al. Lymph node recovery from colorectal tumor specimens: recommendation for a minimum number of lymph nodes to be examined. World J Surg. 2002;26:384-9.

17. Cserni G, Vinh-Hung V, Burzykowski T. Is there a minimum number of lymph nodes that should be histologically assessed for a reliable nodal staging of T3NOM0 colorectal carcinomas? $J$ Surg Oncol. 2002;81:63-9.

18. Norwood MG, Sutton AJ, West K, Sharpe DP, Hemingway D, Kelly MJ. Lymph node retrieval in colorectal cancer resection specimens: national standards are achievable, and low numbers are associated with reduced survival. Colorectal Dis. 2010;12: 304-9.

19. Baxter NN. Is lymph node count an ideal quality indicator for cancer care? J Surg Oncol. 2009;99:265-8.

20. Ricciardi R, Baxter NN. Association versus causation versus quality improvement: setting benchmarks for lymph node evaluation in colon cancer. J Natl Cancer Inst. 2007;99:414-5.

21. Simunovic M, Baxter NN. Lymph node counts in colon cancer surgery: lessons for users of quality indicators. JAMA. 2007;298: 2194-5.

22. Goldstein NS. Lymph node recoveries from 2427 pT3 colorectal resection specimens spanning 45 years: recommendations for a minimum number of recovered lymph nodes based on predictive probabilities. Am J Surg Pathol. 2002;26:179-89.

23. Prandi M, Lionetto R, Bini A, Francioni G, Accarpio G, Anfossi A, et al. Prognostic evaluation of stage B colon cancer patients is improved by an adequate lymphadenectomy: results of a secondary analysis of a large scale adjuvant trial. Ann Surg. 2002; 235:458-63.

24. Wong JH, Bowles BJ, Bueno R, Shimizu D. Impact of the number of negative nodes on disease-free survival in colorectal cancer patients. Dis Colon Rectum. 2002;45:1341-8.

25. Vather R, Sammour T, Kahokehr A, Connolly AB, Hill AG. Lymph node evaluation and long-term survival in Stage II and Stage III colon cancer: a national study. Ann Surg Oncol. 2009;16:585-93.

26. Zaanan A, Meunier K, Sangar F, Flejou JF, Praz F. Microsatellite instability in colorectal cancer: from molecular oncogenic mechanisms to clinical implication. Cell Oncol (Dordr). 2011; 34:155-76.

27. Hermanek P, Sobin LH. International Union Against Cancer (UICC): TNM classification of malignant tumours. 4th ed. New York: Springer-Verlag, 1987.

28. Weiss MM, Hermsen MA, Meijer GA, van Diest PJ. Comparative genomic hybridisation. Mol Pathol. 1999;52:243-51.

29. National Comprehensive Cancer Network (NCCN), Clinical Practice Guidelines in Oncology, version 3.2011. www.ncen. org/professionals/physician_gls/pdf/colon.pdf. Accessed 15 Apr 2011.

30. Moore J, Hyman N, Callas P, Littenberg B. Staging error does not explain the relationship between the number of lymph nodes in a colon cancer specimen and survival. Surgery. 2010;147:358-65.

31. Chang GJ, Rodriguez-Bigas MA, Skibber JM, Moyer VA. Lymph node evaluation and survival after curative resection of colon cancer: systematic review. J Natl Cancer Inst. 2007;99:433-41.
32. Wang J, Hassett JM, Dayton MT, Kulaylat MN. Lymph node ratio: role in the staging of node-positive colon cancer. Ann Surg Oncol. 2008;15:1600-8.

33. West NP, Morris EJ, Rotimi O, Cairns A, Finan PJ, Quirke P. Pathology grading of colon cancer surgical resection and its association with survival: a retrospective observational study. Lancet Oncol. 2008;9:857-65.

34. Jestin P, Pahlman L, Glimelius B, Gunnarsson U. Cancer staging and survival in colon cancer is dependent on the quality of the pathologists' specimen examination. Eur J Cancer. 2005;41: 2071-8.

35. Morris EJ, Maughan NJ, Forman D, Quirke P. Identifying stage III colorectal cancer patients: the influence of the patient, surgeon, and pathologist. J Clin Oncol. 2007;25:2573-9.

36. Etzioni D, Spencer M. Nodal harvest: surgeon or pathologist? Dis Colon Rectum. 2008;51:366-7; author reply 368.

37. Wong SL, Ji H, Hollenbeck BK, Morris AM, Baser O, Birkmeyer JD. Hospital lymph node examination rates and survival after resection for colon cancer. JAMA. 2007;298:2149-54.

38. Boland CR, Goel A. Microsatellite instability in colorectal cancer. Gastroenterology. 2010;138:2073-87 e2073.

39. Pino MS, Chung DC. The chromosomal instability pathway in colon cancer. Gastroenterology. 2010;138:2059-72.

40. Soreide K, Janssen EA, Soiland H, Korner H, Baak JP. Microsatellite instability in colorectal cancer. Br J Surg. 2006;93: 395-406.

41. Parc Y, Gueroult S, Mourra N, Serfaty L, Flejou JF, Tiret E, et al. Prognostic significance of microsatellite instability determined by immunohistochemical staining of MSH2 and MLH1 in sporadic T3N0M0 colon cancer. Gut. 2004;53:371-5.

42. Dolcetti R, Viel A, Doglioni C, Russo A, Guidoboni M, Capozzi E, et al. High prevalence of activated intraepithelial cytotoxic $\mathrm{T}$ lymphocytes and increased neoplastic cell apoptosis in colorectal carcinomas with microsatellite instability. Am J Pathol. 1999; 154:1805-13.

43. Schwitalle Y, Kloor M, Eiermann S, Linnebacher M, Kienle P, Knaebel HP, et al. Immune response against frameshift-induced neopeptides in HNPCC patients and healthy HNPCC mutation carriers. Gastroenterology. 2008;134:988-97.

44. Speetjens FM, Lauwen MM, Franken KL, Janssen-van Rhijn CM, van Duikeren S, Bres SA, et al. Prediction of the immunogenic potential of frameshift-mutated antigens in microsatellite instable cancer. Int J Cancer. 2008;123:838-45.

45. Tougeron D, Fauquembergue E, Rouquette A, Le Pessot F, Sesboue R, Laurent M, et al. Tumor-infiltrating lymphocytes in colorectal cancers with microsatellite instability are correlated with the number and spectrum of frameshift mutations. Mod Pathol. 2009;22:1186-95.

46. Alexander J, Watanabe T, Wu TT, Rashid A, Li S, Hamilton SR. Histopathological identification of colon cancer with microsatellite instability. Am J Pathol. 2001;158:527-35.

47. Jass JR, Do KA, Simms LA, Iino H, Wynter C, Pillay SP, et al. Morphology of sporadic colorectal cancer with DNA replication errors. Gut. 1998;42:673-9.

48. Phillips SM, Banerjea A, Feakins R, Li SR, Bustin SA, Dorudi S. Tumour-infiltrating lymphocytes in colorectal cancer with microsatellite instability are activated and cytotoxic. Br J Surg. 2004;91:469-75.

49. Smyrk TC, Watson P, Kaul K, Lynch HT. Tumor-infiltrating lymphocytes are a marker for microsatellite instability in colorectal carcinoma. Cancer. 2001;91:2417-22.

50. Ogino S, Nosho K, Irahara N, Meyerhardt JA, Baba Y, Shima K, et al. Lymphocytic reaction to colorectal cancer is associated with longer survival, independent of lymph node count, microsatellite instability, and $\mathrm{CpG}$ island methylator phenotype. Clin Cancer Res. 2009;15:6412-20. 
51. Jenkins MA, Hayashi S, O'Shea AM, Burgart LJ, Smyrk TC, Shimizu D, et al. Pathology features in Bethesda guidelines predict colorectal cancer microsatellite instability: a populationbased study. Gastroenterology. 2007;133:48-56.

52. Murphy J, Pocard M, Jass JR, O'Sullivan GC, Lee G, Talbot IC. Number and size of lymph nodes recovered from dukes B rectal cancers: correlation with prognosis and histologic antitumor immune response. Dis Colon Rectum. 2007;50:1526-34.

53. Pihl E, Nairn RC, Hughes ES, Cuthbertson AM, Rollo AJ. Regional lymph node and stromal immunomorphology in colorectal carcinoma and relation to tumour spread. Pathology. $1980 ; 12: 15-21$

54. Eveno C, Nemeth J, Soliman H, Praz F, de The H, Valleur P, Talbot IC, et al. Association between a high number of isolated lymph nodes in T1 to T4 N0M0 colorectal cancer and the microsatellite instability phenotype. Arch Surg. 2010;145:12-7.
55. Soreide K, Nedrebo BS, Soreide JA, Slewa A, Korner H. Lymph node harvest in colon cancer: influence of microsatellite instability and proximal tumor location. World J Surg. 2009;33:2695-703.

56. Beresford M, Glynne-Jones R, Richman P, Makris A, Mawdsley $\mathrm{S}$, Stott $\mathrm{D}$, et al. The reliability of lymph-node staging in rectal cancer after preoperative chemoradiotherapy. Clin Oncol ( $R$ Coll Radiol). 2005;17:448-55.

57. Habr-Gama A, Perez RO, Proscurshim I, Rawet V, Pereira DD, Sousa AH, et al. Absence of lymph nodes in the resected specimen after radical surgery for distal rectal cancer and neoadjuvant chemoradiation therapy: what does it mean? Dis Colon Rectum. 2008;51:277-83.

58. Marks JH, Valsdottir EB, Rather AA, Nweze IC, Newman DA, Chernick MR. Fewer than 12 lymph nodes can be expected in a surgical specimen after high-dose chemoradiation therapy for rectal cancer. Dis Colon Rectum. 2010;53:1023-9. 